\title{
Iridium oxide nanoparticles and polythionine thin film based platform for sensitive Leishmania DNA detection $\uparrow$
}

\author{
Carmen C. Mayorga-Martinez ${ }^{\mathrm{a}}$, Alejandro Chamorro-García ${ }^{\mathrm{a}, \mathrm{b}}$, Lorena Serrano ${ }^{\mathrm{c}}$ Lourdes Rivas $^{\mathrm{a}, \mathrm{b}}$, \\ Daniel Quesada ${ }^{\mathrm{a}, \mathrm{b}}$, Laura Altet ${ }^{\mathrm{c}}$, Olga Francino $^{\mathrm{c}}$, Armand Sánchez $^{\mathrm{c}}$, and Arben Merkoçi*a,d
}

${ }^{a}$ Nanobioelectronics \& Biosensors Group, Institut Catala de Nanociencia i Nanotecnologia (ICN2), Edifici ICN2, Campus UAB, Bellaterra (Barcelona) 08193, Spain.

${ }^{\mathrm{b}}$ Autonomous University of Barcelona, UAB Campus,08193 Bellaterra, Spain.

${ }^{\mathrm{C}}$ Vetgenomics, Edifici Eureka, Parc de Recerca UAB, 08193 Bellaterra (Barcelona); Spain.

${ }^{\mathrm{d} I n s t i t u c i o ́ ~ C a t a l a n a ~ d e ~ R e c e r c a ~ i ~ E s t u d i s ~ A v a n c ̧ a t s ~(I C R E A), ~ P a s s e i g ~ L l u i ́ s ~ C o m p a n y s ~ 23, ~} 08010$ Barcelona, Spain.

* Corresponding Author: Arben Merkoçi, arben.merkoci@icn.cat , Tel: +34937374604. Postal Address: Edifici ICN2, Campus UAB, Bellaterra (Barcelona) 08193, Spain.

This is the accepted version of the article: Mayorga-Martínez, C. at el. An iridium oxide nanoparticle and polythionine thin film based platform for sensitive Leishmania DNA detection in Journal of materials chemistry B (Ed. RSC), vol. 3, issue 26 (July 2015), p. 5166-5171 - Available at: DOI 10.1039/c5tb00545k - This version is published under a "All rights reserved" license. 
An impedimetric label-free genosensor for high sensitive DNA detection is developed. This system is based on a screen-printed carbon electrode modified with thionine layer and iridium oxide nanoparticles ( $\left.\mathrm{IrO}_{2} \mathrm{NP}\right)$. Aminated oligonucleotide probe is immobilized onto the $\mathrm{IrO}_{2}$ NP/polythionine modified electrode and ethanolamine was used as a blocking agent. Different diluted PCR amplified DNA samples have been detected. The selectivity and reproducibility of this system is studied and the system was high reproducible with $\mathrm{RSD} \approx 15 \%$ and sensitive enough while using $2 \%$ of ethanolamine during the blocking step employed for the genosensor preparation.

\section{Introduction}

In the field of biosensors electrochemical impedance spectroscopy (EIS) becomes especially well-suited for the detection of binding events which take place on the electrode's surface ${ }^{1-3}$. This capability to discriminate small changes on surfaces makes EIS capable of detecting interactions of biomolecules close to the surface of the electrodes, and hence enabling a label free detection of a biomolecules thanks just to the changes caused by them due to the biological recognition event. ${ }^{3}$ Specially, impedimetric label free DNA genosensors based on nucleic acid hybridization have received considerable attention due to screening of samples in research of specific DNA sequences related to a specific disease, or state of risk and represent a powerful tool in the field of diagnosis. ${ }^{4-6}$. They offer great advantages due to simplicity, speed, miniaturization, sensitivity, selectivity and low cost for detection of desired DNA sequence or mutant genes. 5,7

The EIS response depends on the modifications of the electrode surface and the interaction of the analyte with the specific recognition elements. Such alterations affect the capability of the redox indicator to reach the electrode surface and consequently its redox conversion. In this way the charge transfer may either increase or decrease. In this type of measurements becomes of special importance the nature of the electrode surface, which determines in great deal the electron transference between the electrode and the redox indicator. It is common to find in the bibliography examples of electrode surface modifications by electropolymerized layers or selfassembled monolayers, in order to enhance the electron transfer between the electrode surface and a redox indicator ${ }^{8}$. With this aim, polythinoine layers have been reported to be used for proper modifications of sensors. ${ }^{9,} 10$ 
The immobilization of the single strand DNA (ss-DNA; to be used as receptor) has been studied over a variety of substrates/ electrodes using various methods such as adsorption, covalent coupling and entrapment ${ }^{11-14}$. However, various issues like poor compatibility of immobilizing materials onto the transducer, poor binding of DNA, creation of inactive or poor conducting layers and less surface area including poor stability were raised. ${ }^{15,16}$ Nanomaterials including metal nanoparticles, nanowires, nanorods, carbon nanotubes, and graphene have been successfully used in impedimetric biosensors to amplify detection signal and achieve lower detection limit due to their high surface area, favorable electronic properties and electrocatalytic activity as well as good biocompatibility induced by the nanometer size and specific physicochemical characteristics ${ }^{17}$. Nanoparticles, due to their small size, display interesting properties at the nanoscale level. First, due to their shape and size they can increase the surface area. Second, thanks to the electrostatic interactions they can be adsorbed or attached onto different surfaces. Third, thanks to the functional groups on their surface, they can be used as anchor points for other molecules ${ }^{18}$.

Here we exploit the iridium oxide nanoparticles ( $\mathrm{IrO}_{2} \mathrm{NPs}$ ) deposited over a polythionine layer which has been electro polymerized onto the carbon transducer with the aim to enhance the properties of the sensor for the detection of amplified DNA. $\mathrm{IrO}_{2} \mathrm{NPs}$ has proved to be good candidates for being applied in biosensing platforms, especially thanks to the citrate groups they present on their surface. The citrate groups allow tailoring of different biomolecules thanks to the non-covalent bond formation between with amino groups on the biomolecule. ${ }^{19,} 20$ The platform developed shows good performance for electrochemical sensing of PCR amplified DNA of dog affected by leishmania, this target is used as a proof a concept. Different dilutions of PCR amplified DNA samples are detected showing high sensitivity while detecting up to 1000 times diluted samples. The system offers the possibility to be applied for diagnostics based on DNA detection, as the pathogen detection (or infectious disease) both in veterinary and human file. 


\section{EXPERIMENTAL}

\section{Apparatus}

Electrochemical experiments were performed using an electrochemical analyzer Autolab 20 (EcoChemie, The Netherlands) which was connected to a personal computer using a software package GPS 4.9 (General Purpose Electrochemical System). Impedance measurements were performed by using an Autolab302 potentiostat/galvanostat/frequency-response analyzer PGST30, controlled by GPES/FRA Version 4.9. A semi-automatic screen-printing machine DEK248 (DEK International, Switzerland) was used for the fabrication of the screen-printed carbon electrodes (SPCEs).

\section{Reagents and solutions}

The reagents used for SPCEs fabrication were: Autostat HT5 polyester sheet (McDermid Autotype, UK), Electrodag 423SS carbon ink, Electrodag 6037SS silver/silver chloride ink, and Minico 7000 Blue insulating ink (Acheson Industries, The Netherlands). Trizma hydrochloride, sodium chloride, sodium citrate, ethylenediamine-tetraacetic acid disodium salt dihydrate (EDTA), ethanolamine, potassium hexachloroiridate-(IV), sodium hydrogencitrate and thionine acetate were purchased from Sigma-Aldrich (St. Louis, MO). Potassium hexacyanoferrate(II) three hydrate, potassium hexacyanoferrate (II) and sulphuric acid were purchased from Panreac Quimica S.A (Barcelona, Spain). Milli-Q water was obtained from purification system and all solutions were prepared with ultra-pure water from a Millipore-MilliQ system. Washing solutions in the label-free assay consisted of TE (0.01M tris and 0.001M EDTA) buffer, pH 8, 2xSSC (300 mM Sodium Chloride and $30 \mathrm{mM}$ sodium citrate) buffer, $\mathrm{pH} 7.2$, containing $1 \%$ ethanolamine and Tris $(0.1 \mathrm{M})$ buffer, $\mathrm{pH} 7.2$ containing $1 \%$ ethanolamine.

\section{Synthesis of iridium oxide nanoparticles}

Potassium hexachloroiridate-(IV) $2.6 \times 10^{-5} \mathrm{M}$ solution was mixed with sodium hydrogencitrate $1.6 \times 10^{-}$

${ }^{2} \mathrm{M}$ solution. The $\mathrm{pH}$ of the red brown solution was adjusted to $\mathrm{pH} 7.5$ with a $0.25 \mathrm{M} \mathrm{NaOH}$ solution and then refluxed in an oil bath with constant stirring for $30 \mathrm{~min}$. As the mixture cooled to room temperature, the $\mathrm{pH}$ was again adjusted to 7.5 with a reflux for $30 \mathrm{~min}$. This procedure was repeated until $\mathrm{pH}$ reached a constant value of 7.5. Finally the solution was refluxed $2 \mathrm{~h}$ more with oxygen bubbling. At the end of this step, a deep blue solution of $\mathrm{IrO}_{2}$ nanoparticles was obtained. The solution was stocked in a glass-stoppered flask and at $4^{\circ} \mathrm{C}$ when not in use. 


\section{PCR amplified products}

The samples used in the study are PCR amplified products of extracted DNA as described in Francino et al 2006. ${ }^{21}$ Briefly, for the DNA extraction, peripheral whole blood was washed in TE buffer pH 8.0 to disrupt the erythrocyte membranes until the leukocyte pellet was white. Leukocytes were then lysed by incubation of the pellet in $0.1 \mathrm{ml}$ of PK buffer $(50 \mathrm{mM} \mathrm{KCl}, 10 \mathrm{mM}$ Tris $\mathrm{pH} 8.0,0.5 \%$ Tween-20 and $23 \mu \mathrm{g}$ of proteinase $\mathrm{K}$ ) at $56^{\circ} \mathrm{C}$ for $5 \mathrm{~h}$. Before running the PCR the proteinase $\mathrm{K}$ was inactivated by incubation of the samples at $90^{\circ} \mathrm{C}$ for $10 \mathrm{~min}$. DNA was then diluted $1 / 5$ in water.

The PCR amplification Leishmania, is the target used as a proof of concept for the developed system. TaqMan-MGB probe (FAM-50-AAAAATGGGTGCAGAAAT-30-non-fluorescent quencher-MGB) and PCR primers (Forward:AACTTTTCTGGTCCTCCGGGTAG and Reverse:ACCCCCAGTTTCCCGCC) were used to target conserved DNA regions of the kinetoplast minicircle DNA from L. infantum. Leishmania primers and probe were added at 900 and $200 \mathrm{nM}$, respectively. PCR was carried out in $25 \mathrm{ml}$ final volume reaction mixture containing TaqMan Universal PCR Master Mix with UNG Amperase (Life technologies). The thermal cycling profile was $50^{\circ} \mathrm{C}$ for $2 \mathrm{~min}, 95^{\circ} \mathrm{C}$ for $10 \mathrm{~min}, 40$ cycles at $95{ }^{\circ} \mathrm{C}$ for $15 \mathrm{~s}$ and $60{ }^{\circ} \mathrm{C}$ for $1 \mathrm{~min}$. Each amplification run contained positive and negative controls.

\section{Genosensor preparation}

Screen printing electrodes were fabricated by sequential deposition of a graphite ink, $\mathrm{Ag} / \mathrm{AgCl}$ ink and insulating ink on a polyester substrate. The polyester substrate was dried at $120^{\circ} \mathrm{C}$ for 45 min (graphite) and $30 \mathrm{~min}(\mathrm{Ag} / \mathrm{AgCl}$ and insulating) after the deposition of each layer.

Before modification with thionine layer and $\mathrm{IrO}_{2} \mathrm{NPs}$, SPCEs were activated by applying a $3 \mu \mathrm{A}$ current during $120 \mathrm{sec}$ in $0.1 \mathrm{M} \mathrm{H}_{2} \mathrm{SO}_{4}$ and then the electrodes were washed with Milli-Q water. $100 \mu \mathrm{L}$ Of thionine solution $0.5 \mathrm{mM}$ was dropped onto the working surface of SPCE, and $20 \mathrm{CVs}$ scans from 0.1 to $-0.55 \mathrm{~V}$ at $50 \mathrm{mV} / \mathrm{s}$ were applied. The electrodes were washed with TE buffer. Afterwards $8 \mu \mathrm{L}$ solution of $\mathrm{IrO}_{2}$ NPs suspension were dropped onto the working surface of SPCE and dried at room temperature (1 hour), and the electrodes were washed with TE buffer.

After modification of SPCE with thionine and $\mathrm{IrO}_{2} \mathrm{NPs}$, adsorption of a $0.5 \mathrm{ng} / \mu \mathrm{L}$ of 3 '-aminated oligonucleotide probe $\left(5^{\prime}\right.$ - $\mathrm{NH}_{2}$-TEG-atatatatatatataTTTTCTGGTCCTCCGGGTAGGGGCGTTCTG3') onto the electrode modified surface was performed, leaving an aliquot of $10 \mu \mathrm{L}$ overnight at $4{ }^{\circ} \mathrm{C}$. Then the electrode was washed with TE buffer $\mathrm{pH}$, to remove the excess of oligonucheotide. Free surface sites were blocked placing a drop of $40 \mu \mathrm{L}$ of ethanolamine solution contained desired 
concentration for $90 \mathrm{~min}$, followed by a washing step with SSC, pH 7.2, buffer containing 1\% ethanolamine.

Hybridization step was performed using synthetic oligonucleotide (for system optimization) and PCR amplified product. The hybridization with synthetic oligonucleotide target was performed at room temperature by placing $30 \mu \mathrm{L}$ of synthetic complementary target solutions (5'TTTCTGCACCCATTTTTCCATTTTCGCAGAACG

CCCCTACCCGGAGGACCAGAAAA-3') in 2xSSC buffer, $\mathrm{pH} 7.2$, containing 1\% ethanolamine, onto the surface of the genosensor for $45 \mathrm{~min}$ and then rinsing with Tris buffer $\mathrm{pH} 7.2$ containing $1 \%$ ethanolamine.

The PCR amplified DNA of dog with Leishmania (140 bp) was used to perform the hybridization instead of commercial oligonucleotide target using the same experimental condition as those used for commercial oligonucleotide. Before the hybridization, the PCR amplified DNA was denatured by heating at $95^{\circ} \mathrm{C}$ for $5 \mathrm{~min}$ followed by immersing in ice until the use. The experimental control was performed using PCR amplified DNA of dog without Leishmania (blank).

\section{Electrochemical measurements}

The electrochemical measurement was performed by electrochemical impedance spectroscopy (EIS) in $1 \mathrm{mM}\left[\mathrm{Fe}(\mathrm{CN})_{6}\right]^{3-14-}$ with $0.1 \mathrm{M} \mathrm{KCl}$ as redox probe. A sinusoidal potential modulation of $\pm 10 \mathrm{mV}$ amplitude in the $0.1 \mathrm{~Hz}$ to $100 \mathrm{kHz}$ frequency range, with logarithmic scale of 10 points per decade, was superimposed onto the formal potential of the redox couple, $\left[\mathrm{Fe}(\mathrm{CN})_{6}\right]^{3-/ 4-}(0.24 \mathrm{~V}$ vs $\mathrm{Ag} / \mathrm{AgCl})$. Nyquist diagrams were also recorded. Electrochemical experiments were carried out at room temperature. 


\section{RESULTS AND DISCUSSION}

Electrochemical impedance spectroscopy (Figure 1) and cyclic voltammetry (Figure S1) were used for the characterization of each fabrication step of the genosensor. Impedance data is usually studied using an equivalent circuit which helps understanding the behavior of the electrode-electrolyte interface onto the biosensor surface. ${ }^{2}$

The observed high electron transfer rate (Figure 1A and Figure S1 A) indicates that the redox mediator doesn't face any obstacle while reaching the surface of the bare electrode. Nevertheless, when the electrode is modified by electrodeposited polythionine layer, the Rct value decreases and a capacitive behavior is observed (Figure 1B and Figure S1B). This demonstrates that the polythionine layer is well deposited and it enhances the electron transfer. However, once $\mathrm{IrO}_{2} \mathrm{NPs}$ are adsorbed onto the modified electrode, a well-defined semicircle (Figure 1C) and a decreasing of the $\Delta \mathrm{E}$ of around $20 \mathrm{mV}$ (Figure S1C) were observed. The improvement of the change transfer was probably due to an electrode effective area increases (see SEM images of Figure 2) and the redox activity of the $\mathrm{IrO}_{2}$ NPS. ${ }^{19,22-24}$ After the oligonucleotide capture probe was attached to the $\mathrm{IrO}_{2}$ NPs a charge transfer increase is observed (Figure 1D and Figure S1D). The negative charges surrounding the $\mathrm{IrO}_{2} \mathrm{NPs}$ allow the attachment of the positively charged amino groups through non-covalent bonding. The charge transfer increase is due to negative charge from oligonucleotide capture probe that acts as an electrostatic barrier between SPCE/PTH and the redox indicator. The blocking effect of ethanolamine was evidenced by a decrease of charge transfer (Figure 1E and Figure S1E). The hybridization of DNA target with the capture probe represents a greater obstacle to the redox mediator due to the negative charge of phosphate backbone of DNA (Figure 1F and Figure 1SF).

The Rct values obtained from Nyquist plots after each surface modification step of the proposed system are shown in Figure S2 of SI. On the basis of the charge transfer kinetics of the $\left[\mathrm{Fe}(\mathrm{CN})_{6}\right]^{3 / 4}$ (redox probe), the faradaic impedance spectra were modelled using the equivalent circuit approach of Randles model modified with Warburg impedance (Figure S2, inset).

The morphological characterization of $\mathrm{IrO}_{2} \mathrm{NPs}$ was studied. Figure 2A displays a transmission electron microscopy (TEM) micrograph, where a clusters morphology of around $20 \mathrm{~nm}$ composed by smaller $\mathrm{IrO}_{2}$ NPs was observed.

$\mathrm{X}$-ray photoelectron spectroscopy and UV-visible spectrophotometry studies also were performed (see Figure S3 and S4). Figure S3 shows the survey XPS analysis (Figure S3A) and high-resolution XPS spectra of the Ir $4 \mathrm{f}$ and $\mathrm{O}$ 1s regions (Figure S3B). The XPS spectra of the Ir 4F region revealed two main features with signals at 62.5 and $65.3 \mathrm{eV}$, which correspond to $\operatorname{Ir} 4 \mathrm{f} 7 / 2$ and Ir $4 \mathrm{f} 5 / 2$ orbitals, 
respectively. Furthermore, the $\mathrm{O} 1 \mathrm{~s}$ region shows two features. The position of the main feature is around $532.5 \mathrm{eV}$ that is similar of $\mathrm{O} 1 \mathrm{~s}$ observed in standard $\mathrm{IrO}_{2}$ single crystal, ${ }^{25}$ the additional feature present the binding energy of $530.2 \mathrm{eV}$. The UV-Vis spectra reveals a characteristic peak of $\operatorname{Ir}(\mathrm{IV})$ oxides with a maximum around $580 \mathrm{~nm}$ (Figure S4). These results are in good agreement with high oxidation state $4^{+}$of iridium reported before. $19,24,25$

The morphological modification of SPE are also studied using scanning electron microscopy (SEM) image. Figure 2B shows a SPE after activation step using $\mathrm{H}_{2} \mathrm{SO}_{4}$, while Figure $2 \mathrm{C}$ displays the polythionine layer as a thin film smoothing the SPE surface. Finally in Figure 2D, the distribution of the $\mathrm{IrO}_{2}$ NPs (brighter dots) onto the SPE / polythionine are observed. Backscatter electrons mode was used for the enhancement of the contrast between $\mathrm{IrO}_{2} \mathrm{NPs}$ and SPE/polythionine surface.

Different dilutions of PCR amplified DNA (1:10, 1:100 and 1:1000) were detected using the system described above. The Rtc values were recorded as a function of PCR amplified DNA (see Figure S5 A) showing lower impedance values for more diluted samples. These results demonstrate that the system is suitable to detect DNA but with a relatively poor reproducibility (RSD of 26\%).

Selectivity is a very important parameter to be considered for DNA genosensors. To evaluate the selectivity of this system, PCR product of dog with (positive) and without (blank) Leishmania were compared. Blank diluted 1:10 had a signal comparable to the positive sample diluted 1:100. (see Figure $\mathrm{S} 5 \mathrm{~B}$ in the supporting information). To improve the selectivity and the reproducibility of this system, the blocking step during genosensor fabrication was modified using $2 \%$ of ethanolamine instead of $0.1 \%$. The resulting data are shown in Figure 3A. The Rct values are quite different for the different dilutions of the PCR product (RSD of 15\%) therefore we could say that this system is more sensitive. A good selectivity of the genosensor toward DNA detection also was evidenced by the neglected responses toward blank (see Figure 3B) while the difference between capture probe and blank was of $0.09 \mathrm{k} \Omega$.

\section{CONCLUSIONS}

A simple and sensitive platform for the impedimetric label free genosensor taking advantage of conventional screen printed carbon electrode (SPCE) modified by polythionine and $\mathrm{IrO}_{2}$ nanoparticles is developed. Although the SPCE electrodes have several advantages such as low cost, miniaturization, mass production, etc. they are not directly suitable as such for impedimetric label free detections, mainly because they present a high resistivity and rough surface. In order to overcome these limitations a 
polythionine layer was electrodeposited on the surface of the working electrode. This modification at the same time decreases the roughness and increases the conductivity of the working electrode. Furthermore, the $\mathrm{IrO}_{2}$ NPs show suitable redox properties in addition to the capability to attach the bioreceptor thanks to the surrounding citrate groups used as capping agent. Moreover, regarding the adsorption of capture DNA probe, the blocking procedure and hybridization steps have been optimized. To improve selectivity, reproducibility and sensitivity the concentration of ethanolamine used as blocking agent was optimized and found to be $2 \%(\mathrm{v} / \mathrm{v})$ the optimal concentration level. This new genosensor is able to detect up to 1000 times diluted samples of PCR amplified DNA.

\section{Acknowledgements}

We acknowledge the E.U.'s support under FP7-SME-2012-1 contract number 315653 "POC4PETS". ICN2 also acknowledges support of the Spanish MINECO under Project MAT2011-25870 and through the Severo Ochoa Centers of Excellence Program under Grant SEV-2013-0295 


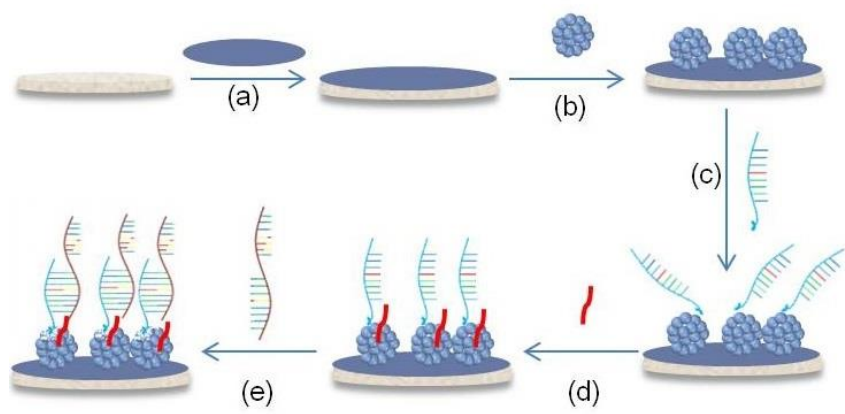

Scheme 1. Schematic representation of the procedure for the impedimetric label-free genosenor fabrication. Thionine electropolymerization (a), deposition of $\mathrm{IrO}_{2} \mathrm{NPs}(\mathrm{b})$, immobilization of ss-DNA (c), blocking step with etanolamine (d) and hybridization with complementary target (e). 

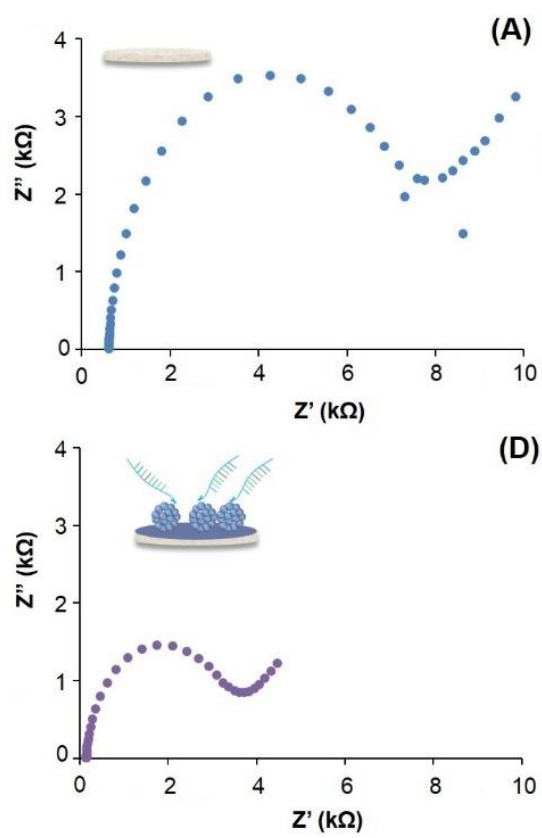

(B)

(E)

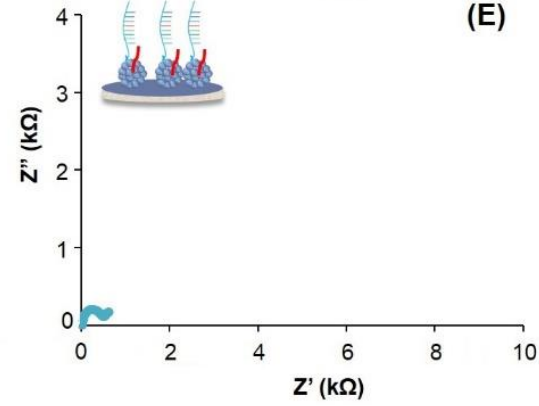

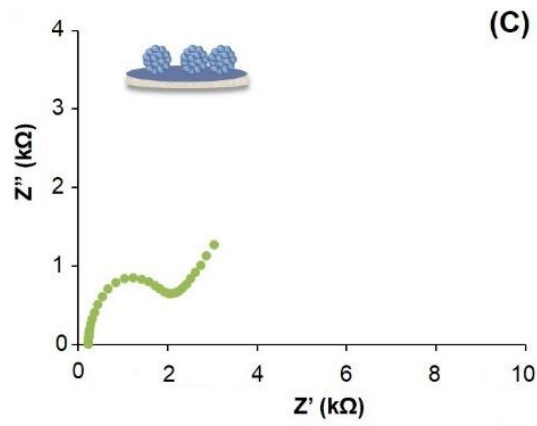

(C)

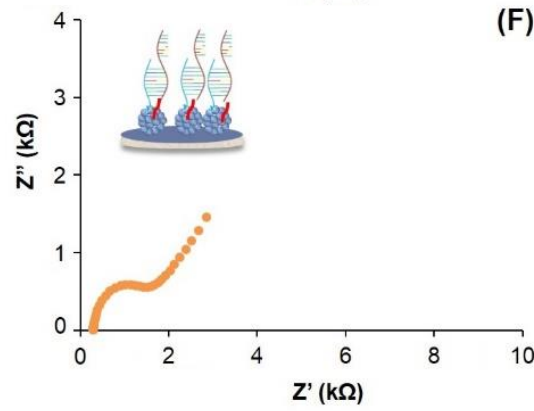

Figure 1. EIS characterization of the bare electrode (A) and after of: electrodeposition of polythionine (B), $\mathrm{IrO}_{2}$ NPs adsorption (C), oligonucleotide probe immobilization (D), blocking step with ethanolamine (E) and hybridization with complementary target $(\mathrm{F})$. 


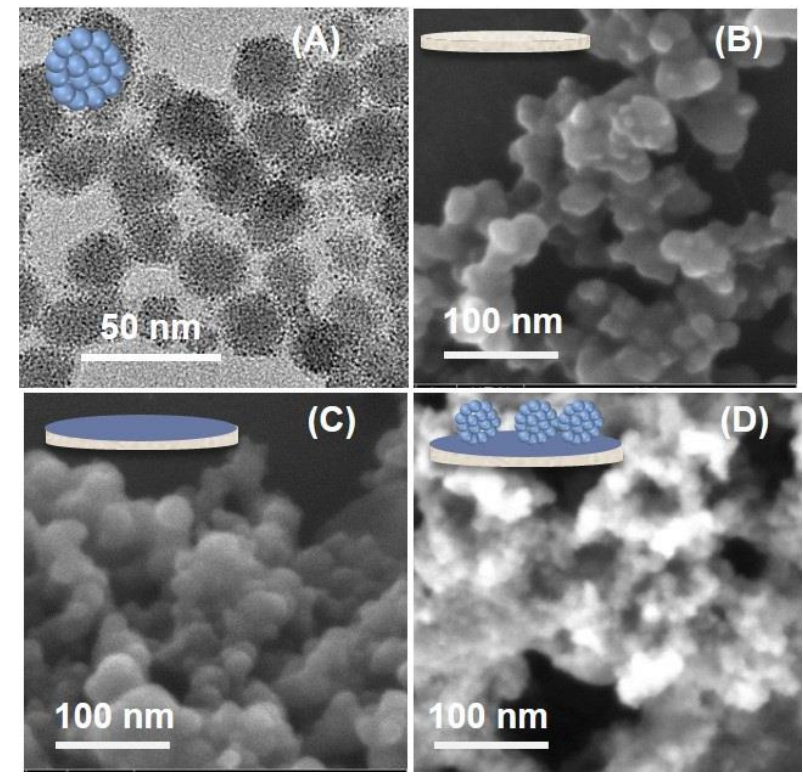

Figure 2. Electrode surface characterizations. (A) TEM images of $\mathrm{IrO}_{2} \mathrm{NPs}$. SEM images of SPCE (B), SPCE with polythionine electrodeposited onto the working electrode surface (C) and SPCE/polythionine with $\mathrm{IrO}_{2}$ NPs adsorbed onto its surface (D). SEM images were taken using backscattered electrons mode. 


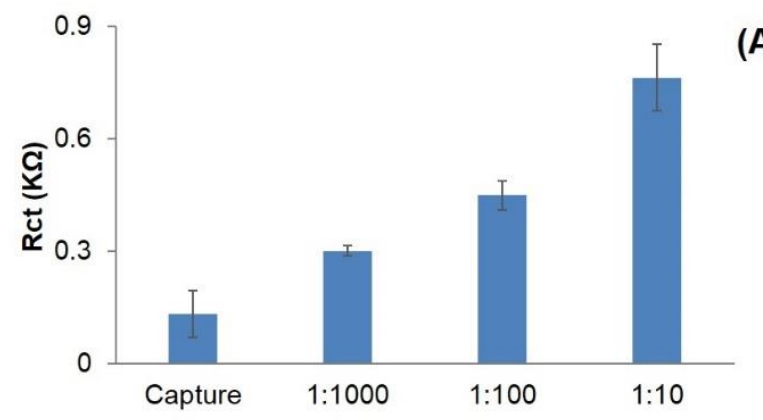

(A)

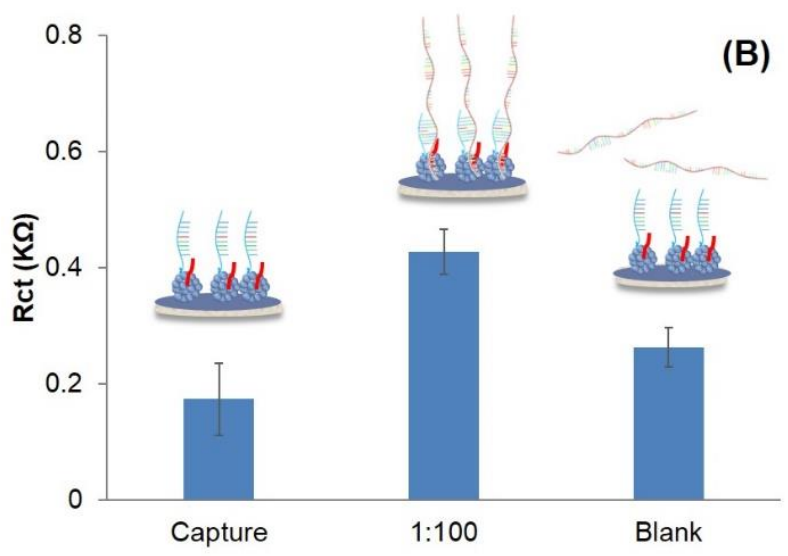

Figure 3. (A) Rct as a function of different dilutions of PCR amplified DNA samples. (B) Comparison of Rct values of the genosensor modified with the capture probe and hybridized with PCR amplified DNA samples of dog affected (Positive) or not (Blank) with Leishmania. Dilutions of 1:10 and 1:100 for the blank and positive samples respectively, and $2 \%$ ethanolamine during the blocking step was used. 


\section{References}

1. A. Bonanni and M. del Valle, Analytica Chimica Acta, 2010, 678, 7-17.

2. B.-Y. Chang and S.-M. Park, Annual Review of Analytical Chemistry, 2010, 3, 207-229.

3. F. Lisdat and D. Schaefer, Analytical and Bioanalytical Chemistry, 2008, 391, 1555-1567.

4. Q. Xu and J. J. Davis, Electroanalysis, 2014, 26, 1249-1258.

5. E. Spain, R. Kojima, R. B. Kaner, G. G. Wallace, J. O'Grady, K. Lacey, T. Barry, T. E. Keyes and R. J. Forster, Biosensors and Bioelectronics, 2011, 26, 2613-2618.

6. J. P. Tosar, G. Brañas and J. Laíz, Biosensors and Bioelectronics, 2010, 26, 1205-1217.

7. T. Ito, K. Hosokawa and M. Maeda, Biosensors and Bioelectronics, 2007, 22, 1816-1819.

8. S. A. Emr and A. M. Yacynych, Electroanalysis, 1995, 7, 913-923.

9. Q. Gao, X. Q. Cui, F. Yang, Y. Ma and X. R. Yang, Biosensors \& Bioelectronics, 2003, 19, 277-282.

10. R. Yang, C. M. Ruan, W. L. Dai, J. Q. Deng and J. L. Kong, Electrochimica Acta, 1999, 44, 1585-1596.

11. H. Peng, C. Soeller, N. Vigar, P. A. Kilmartin, M. B. Cannell, G. A. Bowmaker, R. P. Cooney and J. Travas-Sejdic, Biosensors and Bioelectronics, 2005, 20, 1821-1828.

12. S. Liu, J. Liu, L. Wang and F. Zhao, Bioelectrochemistry, 2010, 79, 37-42.

13. A. Bonanni, M. J. Esplandiu and M. del Valle, Biosensors and Bioelectronics, 2009, 24, 2885-2891.

14. A. C. Honorato Castro, E. G. França, L. F. De Paula, M. M. C. N. Soares, L. R. Goulart, J. M. Madurro and A. G. Brito-Madurro, Applied Surface Science, 2014, 314, 273-279.

15. M. Gebala and W. Schuhmann, Phys. Chem. Chem. Phys., 2012, 14, 14933-14942.

16. T. Doneux, A. De Rache, E. Triffaux, A. Meunier, M. Steichen and C. Buess-Herman, ChemElectroChem, 2014, 1, 147-157.

17. Y. Wang, Z. Ye and Y. Ying, Sensors, 2012, 12, 3449-3471.

18. R. W. Murray, Chemical Reviews, 2008, 108, 2688-2720.

19. L. Rivas, A. de la Escosura-Muñiz, J. Pons and A. Merkoçi, Electroanalysis, 2014, 26, 1287-1294.

20. S. Kurbanoglu, C. C. Mayorga-Martinez, M. Medina-Sánchez, L. Rivas, S. A. Ozkan and A. Merkoçi, Biosensors and Bioelectronics.

21. O. Francino, L. Altet, E. Sánchez-Robert, A. Rodriguez, L. Solano-Gallego, J. Alberola, L. Ferrer, A. Sánchez and X. Roura, Veterinary Parasitology, 2006, 137, 214-221.

22. H. Boo, R.-A. Jeong, S. Park, K. S. Kim, K. H. An, Y. H. Lee, J. H. Han, H. C. Kim and T. D. Chung, Analytical Chemistry, 2006, 78, 617-620.

23. N. Mirbagheri, J. Chevallier, J. Kibsgaard, F. Besenbacher and E. E. Ferapontova, ChemPhysChem, 2014, 15, 2844-2850.

24. Y. Zhao, E. A. Hernandez-Pagan, N. M. Vargas-Barbosa, J. L. Dysart and T. E. Mallouk, The Journal of Physical Chemistry Letters, 2011, 2, 402-406.

25. R.-S. Chen, Y.-S. Huang, Y.-M. Liang, D.-S. Tsai, Y. Chi and J.-J. Kai, Journal of Materials Chemistry, $2003,13,2525-2529$. 